\title{
Increased Healthcare Utilization with Preferred Medication Changes in Patients with Asthma
}

\author{
Christina Huddleston ${ }^{1}$ \\ ${ }^{1}$ Indiana University School of Medicine
}

May 31, 2021

\begin{abstract}
Severe asthma patients have a higher likelihood of emergency department visits and hospitalizations when there is a change in their preferred inhaled corticosteroid. Working to keep their preferred ICS consistent is crucial in reducing overall health care costs.
\end{abstract}

\section{Hosted file}

Maindocument1.docx available at https://authorea.com/users/416799/articles/524197-increasedhealthcare-utilization-with-preferred-medication-changes-in-patients-with-asthma

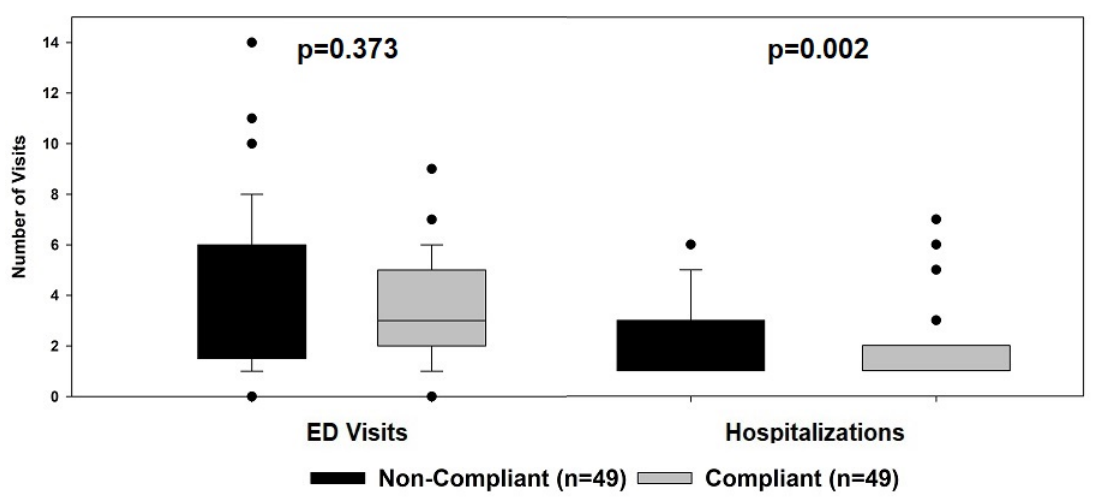




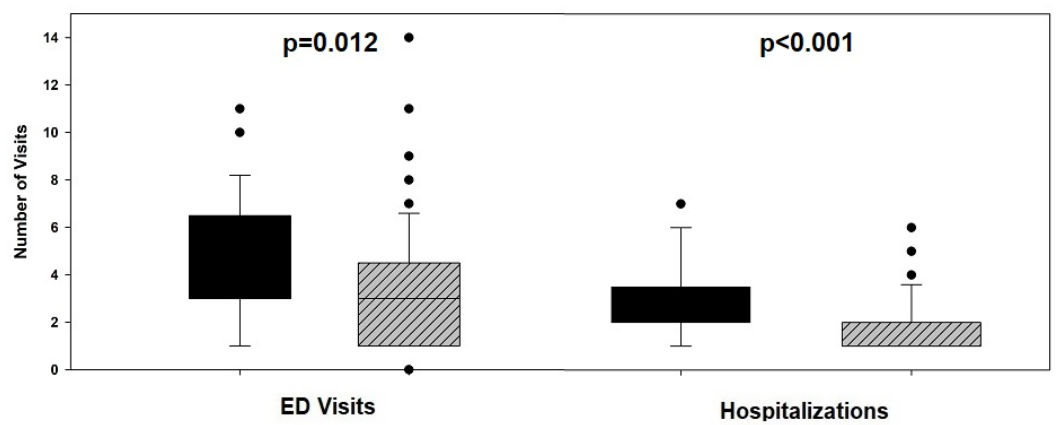

Medication Refill Issue $(n=25)$ एयाय No Refill Issue $(n=73)$ 